\title{
A New grading system based on T2-weighted axial MRI for Cervical Canal stenosis
}

\author{
Shaoyi Wang \\ Qilu Hospital of Shandong University \\ Yunpeng Zhao \\ Qilu Hospital of Shandong University \\ Jianlu Wei \\ Qilu Hospital of Shandong University \\ Xin Pan \\ Qilu Hospital of Shandong University \\ Lin Nie \\ Qilu Hospital of Shandong University \\ Jie Shi \\ Qilu Hospital of Shandong University \\ Lei Cheng ( $\nabla$ wsyspine@163.com ) \\ Qilu Hospital of Shandong University
}

\section{Research article}

Keywords: Central Canal Stenosis, Axial MRI, Grading, Cervical spine

Posted Date: August 1st, 2020

DOI: https://doi.org/10.21203/rs.3.rs-48517/v1

License: (c) (i) This work is licensed under a Creative Commons Attribution 4.0 International License. Read Full License 


\section{Abstract}

Background: Cervical Canal Stenosis (CCS) is a common cervical disease that occurs during and after middle age. There are a variety of grading systems and Measurement methods based on X-ray, Computed Tomography(CT) for cervical canal stenosis. Although many authors measured and classified cervical canal stenosis on the basis of T2-weighted sagittal MRI after the appearance of magnetic resonance, the research on Cervical Canal Stenosis remains to be improved. To explore a more detailed grading system on MRI for cervical canal stenosis and could be used to the clinical diagnosis and treatment.

Methods: We retrospectively studied 200 patients with cervical spinal stenosis. Cervical canal stenosis was classified according to the T2-weighted axial MRI with the most serious compression into the following grades: grade 0,normal; grade 1, mild canal stenosis with obliteration of anterior or posterior of cerebrospinal fluid (CSF) space ; grade 2, moderate canal stenosis with obliteration of both sides of the CSF space but no significant changes in spinal morphology; Grade 3, severe canal stenosis with spinal cord deformity, 3A the oppression ratio of cervical spinal cord is under $50 \%$, 3B the angle of the protrusion less than $90^{\circ}$; Grade 4, serious canal stenosis with spinal cord deformity and the oppression ratio of cervical spinal cord is exceeding $50 \%$, $4 \mathrm{~A}$ the non-ossification protrusion, $4 \mathrm{~B}$ the ossific protrusion. We collected the relevant clinical and imaging data of the patients and analyzed the relationship between them and our new grading system. Patients were followed up one year later.

Results: Our new grading system was easy to learn and communication. The the ICC reliabilities between six readers was between 0.817-0.865. And the Effective sagittal spinal canal was significantly different along with our grades at each disc level. In terms of clinical data, our grading system is correlated with the patient's preoperative mJOA score and had impact on the choice of surgical strategy.

Conclusions: We suggest our new grading system can provided as a reliable assessment that can guide clinical treatment for Cervical Canal Stenosis.

\section{Background:}

Degenerative cervical myelopathy (DCM) is a progressive spinal cord condition caused by cervical canal stenosis (CCS) or other degenerative pathologies of the cervical spine[1,2]. CCS may occur for a variety of reasons, such as degenerative disc bulging, degenerative changes in the facet joint, ossification of the posterior longitudinal ligament (OPLL) or cervical spondylosis[1, 3]. Anterior decompression by discectomy or corpectomy and posterior decompression by laminectomy or laminoplasty are surgical methods for treating CCS[4].

Previous studies have described numerous methods of assessing the degree of cervical canal stenosis. Early studies were based on X-ray; Boijson[5] has first measured the sagittal diameter of the cervical spinal canal on a cervical lateral radiograph. And Pavlov et al and Torg et al used the ratio of the sagittal diameter of the cervical canal divided by the corresponding diameter of the vertebral body to indicate the degree of cervical canal stenosis[6-8].

Into the 21th century, MRI began to gradually rise and gradually to be the most commonly used imaging method for the CCS. Magnetic Resonance Imaging(MRI) measures not only the width and length of the spinal canal but also depicts in detail the soft tissue, intervertebral disks, the spine cord and ligaments which cannot be reflected by X-ray or CT[8-10]. Therefore, many doctors began to evaluate CCS from the perspective of MRI. Claus Muhle et al classified cervical canal stenosis from T2-weighted sagittal MRI according to the following grading system: grade 0, normal; grade 1, partial obliteration of the anterior or posterior subarachnoid space; grade 2, complete obliteration of the anterior or posterior subarachnoid space; and grade 3, cervical cord compression or displacement[11]. Janes JG et al measured the ratio of vertebral canal area and cord canal area and concluded it was a better parameter to predict the location of cervical canal 
stenosis compared to only the sagittal plane of canal height[12]. Yusuhn Kang et al described the CCS from T2-weighted sagittal MRI as the following grading system: grade 0 , absence of canal stenosis; grade 1, subarachnoid space obliteration exceeding 50\%; grade 2, spinal cord deformity; and grade 3, spinal cord signal change[13]. Karpova, A et al found quantitative magnetic resonance imaging methods, such as compression ratio (CR), maximum canal compromise (MCC), and maximum spinal cord compression (MSCC), can used to assess cervical canal stenosis and correlated well with clinical severity of cervical myelopathy[14].

As mentioned above, the MRI grading system of CCS is now centered on the T2-weighted sagittal image. However sagittal images usually show the compression of the entire cervical spine, and axial images can cover the morphology of protrusions and the detail of the stenosis[15-17]. Josef Bednarik et al have predicted the progression of spondylotic cervical myelopathy from T2-weighted axial MRI[18].

Therefore, we made a new grading system for cervical canal stenosis that is based on the T2-weighted axial MRI. The purpose of this study was to propose a more detailed grading system on MRI for cervical canal stenosis and could be used to the clinical diagnosis and treatment.

\section{Methods:}

\section{MRI Grading System for Cervical Canal Stenosis}

Cervical canal stenosis was classified into the following grading system according to the MRI on T2-weighted axial images with the most serious oppression(Fig. 1): grade 0, absence of canal stenosis without obliteration of Cerebrospinal fluid(CSF) space; grade 1, mild canal stenosis with obliteration of anterior or posterior of CSF space; grade 2 , moderate canal stenosis with obliteration of both sides of the CSF space but no significant changes in spinal morphology; grade3A: the degree of cervical spinal cord compression is below $50 \%$ (the cervical spinal cord compression ratio is between $0.4-0.2$ ), grade $3 \mathrm{~B}$, severe canal stenosis with spinal cord deformity and the angle of the compressive mass less than $90^{\circ}$; grade 4, severe cervical spinal stenosis with cervical spinal cord malformation, cervical spinal cord compression is over $50 \%$ 口the cervical spinal cord compression ratio is less than $0.2 \square$ grade $4 \mathrm{~A}$, the nature of the herniation is non-bony(Fig. 2), grade 4B: the herniation is the ossify mass.

\section{Case Selection}

This study was approved by our Ethics Committee, and informed consent was not required. We retrospectively studied the MRI of 230 patients in our hospital from January 2016 to December 2017. Among the selected 230 patients, 30 patients with either history of trauma, other surgery, or serious heart and lung disease. As a result, 200 patients were included in the final analysis (150 men and 50 women; mean age, $53.635 \pm 7.599$ years). Among the 200 patients,149 patients have received surgery finally (Table 1). 
Table 1

Patient demographics

\begin{tabular}{|ll|}
\hline Total patients & 200 \\
Age(y), mean \pm SD (rang) & $53.635 \pm 7.599$ \\
Gender(M/F) & $150 / 50$ \\
Operation & 149 \\
& \\
& \\
Non-operation & 51 \\
Pre-mJOA score & $13.345 \pm 2.024$ \\
\hline mJOA, modified Japanese Orthopaedic Association. \\
\hline SD, standard deviation. \\
\hline
\end{tabular}

\section{Image Acquisition}

In our hospital, the MRI scans were performed with either a 3.0 T unit equipment (SIEMENS, Magnetom Verio 3.0, Germany) with a 3T Neck Matrix coil and two imaging protocols of the entire cervical spine: a sagittal T1-weighted (700/10[repetition time msec/echo time msec]) tubro spin echo and T2-weighted (3000/113.0) tubro spin echo. The slice thickness was $3.0 \mathrm{~mm}$, with a $1 \mathrm{~mm}$ interslice gap.

To quantify the stenosis, The shortest anteroposterior diameter of the cervical spinal cord was set as AP, the widest transverse diameter was set as W, and AP/W was used to evaluate the degree of cervical spinal cord compression(Figure $3)$. The value of normal AP/W should be above 0.5 . When AP/W $<0.4$, cervical spinal stenosis is considered $[18,19]$.

\section{Image analysis}

Six observers with different levels of experience, one radiology resident, three Orthopaedic surgeons, and two experienced musculoskeletal radiologists with 5 and 10 years of experience, independently read the images without knowing the patient's condition and age. We introduced our grading system to the readers in the form of words and sketches, some typical examples for a better understanding. The readers were asked to assess the degree of cervical canal stenosis according to above-mentioned grading system at five sequential levels $(C 2 / 3, C 3 / 4, C 4 / 5, C 5 / 6, C 6 / 7)$, and measure the diameter of effective sagittal spinal canal(ESSC) on the T2W axial MRI. To minimize observer memory bias, one reader read the images twice with an interval of 2 months.

\section{Clinical correlation}

Clinical symptoms were collected and physical examinations were performed by a orthopedic resident with 4 years of experience and reviewed by a deputy chief physician with more than 10 years of experience. We collected the general information and positive clinical manifestations (weakness, parethesia, numbness and balance disorders) to calculate the preoperative mJOA (modified Japanese Orthopaedic Association Scores) score for each patient. For surgical patients, we also recorded their surgical procedures and treatment segments. After 1 year we contacted all the patients by phone, and collected their mJOA scores and asked them whether had an operation and the surgical produres.

\section{Statistical Analysis}


Intraobserver and interobserver reliability of the new MRI grading system were analyzed using intraclass correlation coefficient (ICC). According to Landis and Koch, the agreement was rated as follows: ICC values of 0-0.2 indicated slight agreement, 0.21-0.4 indicated fair agreement, 0.41-0.60 indicated moderate agreement, 0.61-0.8 indicated substantial agreement, and 0.81 or greater indicated excellent agreement[20]. For analysis of the relationship between our grading system and patients' characteristics, such as preoperative mJOA score and surgical procedures, and the MRI findings we used categoric regression analysis and nonparametric correlation analysis (Spearman correlation) to calculate the correlation coefficients $(R)$. An R between 0.7 and 0.9 indicated a relatively high correlation and $R>0.9$ indicated a very high correlation. The level of correlation significance was 0.01. GraphPad Prism (GraphPad Software Inc, San Diego, CA, USA) was used for statistical analyses.

\section{Results}

\section{Interobserver Agreement}

Primary evaluation showed an almost perfect ICC reliability between six readers. Except for the C4/5 disc level ( 0.781$)$, the ICC reliabilities between six readers was almost perfect (0.817-0.865) at all disc levels (Table 2). The second step, we asked all readers reclassify all the patients' images within 2 months. And the ICC ranged from 0.792 to 0.859 , indicating a better agreement. ICC values were as follow: 0.859 at C2/3 disc level, 0.843 at C3/4 disc level, 0.792 at C4/5 disc level, 0.834 at C5/6 disc level, and 0.821 at C6/7 disc level and all of above were highly statistically significant $(\mathrm{P}<$ 0.05).

Table 2

ICC reliabilities for inter-reader agreement.

\begin{tabular}{|lll|}
\hline \multicolumn{3}{|c}{ agreement. } \\
\hline $\mathrm{C} 2 / 3(\mathrm{IC}=146)$ & 0.865 & $<0.01$ \\
\hline $\mathrm{C} 3 / 4(\mathrm{n}=200)$ & 0.853 & 0.012 \\
\hline $\mathrm{C} 4 / 5(\mathrm{n}=200)$ & 0.781 & 0.027 \\
\hline $\mathrm{C} 5 / 6(\mathrm{n}=200)$ & 0.829 & 0.019 \\
\hline $\mathrm{C} 6 / 7(\mathrm{n}=200)$ & 0.817 & $<0.01$ \\
\hline
\end{tabular}

Image Analysis

To verify if there are differences between all groups according to our grading system, Effective sagittal spinal canal (ESSC) was measured in the next step and was compared between our grades at each disc level by one-way ANOVA. Table 3 indicated that not all disc levels had all of our grades except the disc C4/5. And ESSC was significantly different along with our grades at each disc level. In addition, in disc C3/4, C4/5, C5/6 there were a relatively high correlation between stenosis grades and ESSC. Along with the stenosis grades, the ESSC decreased. In the disc C3/4, the R score was $0.813,0.780$ in disc $C 4 / 5,0.826$ in disc $C 5 / 6$, and 0.709 in disc C6/7. It indicated a relatively high correlation. 
Table 3

Effective sagittal spinal canal according to our new cervical Canal Stenosis grading system at each disc level.

\begin{tabular}{|c|c|c|c|c|c|c|c|c|c|}
\hline & Grade 0 & Grade 1 & Grade 2 & Grade 3A & Grade 3B & Grade 4A & Grade 4B & $\begin{array}{l}P \\
\text { value }\end{array}$ & $\begin{array}{l}\mathrm{R} \\
\text { score }\end{array}$ \\
\hline $\mathrm{C} 2 / 3$ & $\begin{array}{l}11.26 \pm \\
1.26\end{array}$ & $\begin{array}{l}9.82 \pm \\
1.49\end{array}$ & $\begin{array}{l}9.41 \pm \\
0.34\end{array}$ & $\begin{array}{l}8.13 \pm \\
0.28\end{array}$ & -ー-ー & ---- & ---ー & $<0.01$ & 0.236 \\
\hline $\mathrm{C} 3 / 4$ & $\begin{array}{l}11.00 \pm \\
0.81\end{array}$ & $\begin{array}{l}9.59 \pm \\
0.44\end{array}$ & $\begin{array}{l}9.16 \pm \\
0.30\end{array}$ & $\begin{array}{l}7.10 \pm \\
1.22\end{array}$ & $\begin{array}{l}5.25 \pm \\
0.35\end{array}$ & $\begin{array}{l}4.17 \pm \\
0.38\end{array}$ & $\begin{array}{l}3.73 \pm \\
0.41\end{array}$ & $<0.01$ & 0.813 \\
\hline C4/5 & $\begin{array}{l}10.48 \pm \\
0.59\end{array}$ & $\begin{array}{l}9.67 \pm \\
0.45\end{array}$ & $\begin{array}{l}9.12 \pm \\
0.50\end{array}$ & $\begin{array}{l}7.49 \pm \\
1.20\end{array}$ & $\begin{array}{l}6.48 \pm \\
1.05\end{array}$ & $\begin{array}{l}2.95 \pm \\
0.78\end{array}$ & $\begin{array}{l}2.63 \pm \\
0.18\end{array}$ & $<0.01$ & 0.780 \\
\hline C5/6 & $\begin{array}{l}10.56 \pm \\
0.60\end{array}$ & $\begin{array}{l}9.45 \pm \\
0.37\end{array}$ & $\begin{array}{l}9.22 \pm \\
0.42\end{array}$ & $\begin{array}{l}7.40 \pm \\
1.12\end{array}$ & $\begin{array}{l}5.33 \pm \\
0.50\end{array}$ & $\begin{array}{l}3.98 \pm \\
0.79\end{array}$ & $\begin{array}{l}3.28 \pm \\
0.18\end{array}$ & $<0.01$ & 0.826 \\
\hline C6/7 & $\begin{array}{l}10.84 \pm \\
0.87\end{array}$ & $\begin{array}{l}9.68 \pm \\
0.48\end{array}$ & $\begin{array}{l}9.14 \pm \\
0.41\end{array}$ & $\begin{array}{l}7.89 \pm \\
0.90\end{array}$ & $\begin{array}{l}7.55 \pm \\
1.05\end{array}$ & $\begin{array}{l}4.80 \pm \\
0.10\end{array}$ & -ー-ー & $<0.01$ & 0.709 \\
\hline
\end{tabular}

Table 4 has shown the distribution of the stenosis grades in each cervical disc level based on our new grading system. In general, grade $3 \mathrm{~A}$ was most frequently noted except grade 0 . Then was grade 2 and grade 1 . In the disc C2/3 and C3/4, grade 1 was the most frequently noted grade. And in the grade $C 4 / 5$ and C5/6, grade $3 A$ was the most. Grade 2 was found at most in the disc C6/7. Series stenosis grade, such as grade 4 , was only found in the disc $C 4 / 5$ and $C 5 / 6$. And in the disc $\mathrm{C} 4 / 5$ and $\mathrm{C} 5 / 6$, the incidence of stenosis (stenosis grade was above grade 0 ) was significantly higher than any others, which indicated than these disc levels had a evident large burden of stenosis others. And in the disc $\mathrm{C} 2 / 3$, the overall burden of stenosis was lightest.

Table 4

Distribution of the stenosis grades in each cervical disc.

\begin{tabular}{|c|c|c|c|c|c|c|c|c|}
\hline $\begin{array}{l}\text { Cervical } \\
\text { level }\end{array}$ & Grade 0 & Grade 1 & Grade 2 & Grade 3A & $\begin{array}{l}\text { Grade } \\
\text { 3B }\end{array}$ & Grade 4A & $\begin{array}{l}\text { Grade } \\
\text { 4B }\end{array}$ & Total \\
\hline $\mathrm{C} 2 / 3$ & $111(75.51 \%)$ & $25(17.01 \%)$ & $8(5.44 \%)$ & $2(1.36 \%)$ & & & & 146 \\
\hline $\mathrm{C} 3 / 4$ & 66(33.00\%) & $47(23.50 \%)$ & $42(21.00 \%)$ & $36(18.00 \%)$ & $2(1.00 \%)$ & $4(2.00 \%)$ & $3(1.50 \%)$ & 200 \\
\hline $\mathrm{C} 4 / 5$ & $23(11.50 \%)$ & $46(23.00 \%)$ & $48(24.00 \%)$ & $60(30.00 \%)$ & $6(3.00 \%)$ & $13(6.50 \%)$ & $4(2.00 \%)$ & 200 \\
\hline C5/6 & $20(10.00 \%)$ & $26(13.00 \%)$ & $51(25.50 \%)$ & $64(32.00 \%)$ & $6(3.00 \%)$ & $31(15.50 \%)$ & $2(1.00 \%)$ & 200 \\
\hline C6/7 & $57(28.50 \%)$ & $51(25.50 \%)$ & $45(22.50 \%)$ & $43(21.50 \%)$ & $2(1.00 \%)$ & $2(1.00 \%)$ & & 200 \\
\hline Overall & 277 & 195 & 194 & 205 & 16 & 50 & 9 & 946 \\
\hline
\end{tabular}

\section{Evaluation of Patient Symptoms}

To explore the relationship between our grading system and the symptoms of Cervical Canal Stenosis (CCS), we ranked patients according to the grade of the most serious stenosis and analyzed some clinical indicators such as mJOA score, age, gender and surgery (Table 5). 
Table 5

Correlation Between Grade of Stenosis and Patient Information

\begin{tabular}{|c|c|c|c|c|c|c|c|c|}
\hline & $\begin{array}{l}\text { Grade } \\
0\end{array}$ & Grade 1 & Grade 2 & Grade $3 A$ & Grade 3B & Grade 4A & Grade 4B & $\begin{array}{l}\mathrm{P} \\
\text { value }\end{array}$ \\
\hline $\mathrm{n}$ & 0 & 16 & 29 & 90 & 16 & 42 & 7 & \\
\hline Pre-mJOA ${ }^{a}$ & -- & $\begin{array}{l}16.19 \pm \\
0.75\end{array}$ & $\begin{array}{l}14.83 \pm \\
0.76\end{array}$ & $\begin{array}{l}13.73 \pm \\
1.46\end{array}$ & $\begin{array}{l}11.69 \pm \\
1.54\end{array}$ & $\begin{array}{l}11.55 \pm \\
1.64\end{array}$ & $\begin{array}{l}10.29 \pm \\
1.13\end{array}$ & $\begin{array}{l}P< \\
0.01\end{array}$ \\
\hline $\begin{array}{l}\text { High T2 } \\
\text { signal }\end{array}$ & 0 & 0 & 0 & $50(55.56 \%)$ & $16(100 \%)$ & $35(83.33 \%)$ & $7(100 \%)$ & \\
\hline operation & 0 & $3(18.75 \%)$ & $20(68.97 \%)$ & $59(65.56 \%)$ & $16(100 \%)$ & $42(100 \%)$ & $7(100 \%)$ & \\
\hline Pre-mJOA & -- & $\begin{array}{l}15.00 \pm \\
0.00\end{array}$ & $\begin{array}{l}14.55 \pm \\
0.60\end{array}$ & $\begin{array}{l}13.12 \pm \\
1.39\end{array}$ & $\begin{array}{l}11.69 \pm \\
1.54\end{array}$ & $\begin{array}{l}11.55 \pm \\
1.64\end{array}$ & $\begin{array}{l}10.29 \pm \\
1.11\end{array}$ & $\begin{array}{l}P< \\
0.01\end{array}$ \\
\hline Anterior & -- & $3(100 \%)$ & $27(93.10 \%)$ & $82(82.22 \%)$ & $16(100 \%)$ & $18(42.86 \%)$ & $1(14.29 \%)$ & \\
\hline IRA & -- & $100 \%$ & $65 \%$ & $68.05 \%$ & $41.66 \%$ & $52.87 \%$ & $40 \%$ & \\
\hline Posterior & -- & 0 & $2(6.90 \%)$ & $16(17.78 \%)$ & 0 & $24(57.14 \%)$ & $6(85.71 \%)$ & \\
\hline IRP & -- & -- & $50 \%$ & $66.66 \%$ & -- & $60.97 \%$ & $56.39 \%$ & \\
\hline$n^{c}$ & -- & 13 & 7 & 31 & -- & -- & -- & \\
\hline SR & -- & 0 & $2(28.57 \%)$ & $14(45.16 \%)$ & -- & -- & -- & \\
\hline Anterior & -- & -- & $2(100 \%)$ & $11(78.57 \%)$ & -- & -- & -- & \\
\hline Posterior & -- & -- & 0 & $3(21.42 \%)$ & -- & -- & -- & \\
\hline \multicolumn{9}{|c|}{ a, the preoperative mJOA score of all patients. } \\
\hline \multicolumn{9}{|c|}{ b, the preoperative mJOA score of patients undergoing surgery. } \\
\hline \multicolumn{9}{|c|}{ IRA: Improvement rate of patients undergone anterior surgery after 1 year. } \\
\hline \multicolumn{9}{|c|}{ IRP: Improvement rate of patients undergone posterior surgery after 1 year. } \\
\hline \multicolumn{9}{|c|}{ c, the number of unoperated patients } \\
\hline SR: Surgery & after 1 & & & & & & & \\
\hline
\end{tabular}

Among the cases we observed, patients with grade 3A stenosis were the most common (90/200). Preoperative mJOA score in all patients was significantly different along with our grades $(P<0.01)$. However, there was no high correlation that preoperative mJOA score decreased as the grading system increased $(R=0.5351)$. In surgical patients, the Pre-mJOA score was also decreased along with the grading system, and the Pearson R score was 0.4156 . All of patients with 4B,3B had high T2 signal in MRI. And 83.33\% of patients with 4A had high T2 signal in MRI. Although there was no significant difference in ESSC between grade 1 and 2, about $68.97 \%$ of patients with grade 2 has received surgery while only $18.75 \%$ of patients with grade 1 . All patients with grade $4 \mathrm{~A}$ and $4 \mathrm{~B}$ has received surgery, and for most of patients with 4B posterior decompression was a good choice. For patients with grade 1, 2 and 3B, anterior decompression can solve problem very well. For patients with grade $4 \mathrm{~A}$, the choice of surgical approach has no significantly different. After 1 year, we contacted with these patients again. We found that both anterior and posterior surgery can achieve a better improvement rate, except the patients with $4 \mathrm{~B}$ was $40 \%$, and patients with $3 \mathrm{~B}$ was $41.66 \%$. In outpatients, about $31.37 \%$ of them had received a surgery treatment during one year. $45.16 \%$ of patient with 2 and $28.67 \%$ of patient with 1 . Gender and ages do not have difference in our grading system. 


\section{Discussion}

Degenerative cervical myelopathy (DCM) is a common degenerative disorder, with the aging of the population getting worse its incidence is also increasing year by year[21], which is characterized by numbness, limb weakness, walking difficulties, and serious paralysis[22]. CSS is an important cause of DCM, which bring a serious burden to the family and community[23-25].

Although several research groups have studied the relationship between the radiologic parameters and clinical manifestations or outcomes, radiological findings still can not be used as a predictive factor in clinical severity or decide on treatment options $[5,6,11,13,26]$. At the beginning, most of the research on CCS focused on the X-ray and CT without considering the epidural fat between the dural sac and the bony spinal canal[5-7] $[27,28]$. After entering the 21 th century with the rise of MRI technology, the assessment of CSS resumed in various studies. Laurencin et al contrasted the interobserver agreement among the qualitative evaluation of cervical spinal stenosis on CT myelograms and MR images[26]. It showed MRI fared slightly better than CT myelograms with regard to level of stenosis. But it didn't come up with a specific grading system only with a degree (none, mild, moderate, or severe), and the observed kappa values were 0.31 and 0.22 respectively. The fair agreement also indicated the importance of a unified and specific standard that can be accepted and used in practical application. The Mentioned previously grading system of Claus Muhle et al was based on the occlusion of the subarachnoid space around the spinal cord and Spinal compression or displacement at maximum flexion and extension[11]. This classification indicated that cervical spinal motion may contribute to the development of cervical spondylotic myelopathy but had no use to the diagnosis of CCS. Yusuhn Kang et al classified CCS into 4 grades according to the T2-weighted sagittal images considering subarachnoid space, spinal compression and the change of the spinal cord signal[13]. However, although there are many scholars had assessed the cervical stenosis based on sagittal MRI, but they did not further verify if there were the differences between their grading systems, and the guiding function to clinical diagnosis and treatment. In addition to there is no consensus and universally adopted scheme of classification between radiologists and clinicians. This will hinder the communication between doctors, as well as further research on CCS. Therefore, it is still necessary to continue to explore a more practical and reliable grading system.

We applied our CCS grading system for T2-weighted axial images, decided by Cerebrospinal fluid (CSF) space, spine cord form and the character of the protrusion. We assumed that the remaining CSF space of the dural sac and the character of the protrusion were an important factor in predicting the development of the CCS, and the spine cord form was the key to determine the patient's current treatment strategy.

We have repeatedly explored how to ensure our new grading system is consistent with the degree of stenosis and makes it easier to understand. According to our results, the Interobserver variability among readers with different levels was in a range of $75 \%-86 \%$, which was a fairly high level of agreement. This finding implied that the grading system was sufficient as a reliable method to assess the degree of CCS and could be learned and understood easily.

About the clinical severity of CCS and the effective sagittal spinal canal(ESSC), many studies have mentioned the relationship between the symptoms of spinal stenosis and $\operatorname{ESSC}[5,26]$. Our purpose is not to prove the diagnostic value of ESSC for CCS, but rather to compare the differences of CCS among all levels according to our new grading system. Statistically significant differences were recorded for ESSC between CCS grades at C2-C7 disc levels (Table 3). The difference between grade 1 and grade 2 is not obvious. We consider this may be because the cerebrospinal fluid space (CSF) on one side is small, and the differences between individuals further narrow this difference. However, there was a difference between grade 1 and grade 2 in clinical data analysis. There is only $18.75 \%$ of patients with grade 1 finally had surgery by December, 2017, compared with nearly $70 \%$ of patients with grade 2 . According to the Muhle[11], with the anterior or posterior of cerebrospinal fluid space, when patients with grade 1 stenosis do flexion and extension activities 
the cervical canal cord still has a full activity space. But patients with grade 2 with no cerebrospinal fluid space of all cases, when patients do activities in flexion and extension, anterior and posterior cord impingement can be observed, thus inducing DCM or other symptoms of spinal cord[29]. Therefore, we insist grade 1 and grade 2 . In addition, due to the small number of cases in grade $4 \mathrm{~B}$, this result may be biased.

For a new classification system, the information to be conveyed should not only be concise, but also play a guiding role in clinical treatment. Some scholars thought that the severity of spinal cord compression is proportional to the severity of clinical symptoms and the high signal intensity on the T2-weighted MRI indicates a poor prognosis[30, 31]. Once the oppression occurs, the condition of most patients will gradually deteriorate within a few years[18, 32]. Grade 3 and 4 in our grading system are mainly based on the degree of compression of the spinal cord. According to our results (Table 5), once the stenosis reaches grade 4, the patient's mJOA score will drop rapidly, and always accompanied by a stenosis of the adjacent stage (the data is not shown). At this time a single-stage decompression cannot meet the surgical needs. And there is evidence that about $5 \%$ of asymptomatic spinal cord compression patients begin to have symptoms each year[18]. In other words, patients with grade 2 stenosis are more likely to progress to higher grades of cervical spinal stenosis and myelopathy. Our results also show doctors will suggest that most patients with grade 2 stenosis to choose a surgical treatment. This is another reason why we still have to distinguish between grade 1 and 2 . Therefore, we recommend active drug intervention for patients with grade 2 stenosis and surgical treatment if necessary. Although no evidence of the superiority of anterior versus posterior surgery can be drawn for patient with multilevel CCS, the role of surgery in stopping the prevention of DCM symptoms has been widely recognized[33].

In terms of 1-year improvement rate, patients with grade 3B had a low improvement rate. We considered that patients with $3 \mathrm{~B}$ were more likely to have severe never damage. Because a sharp injury was more severe than blunt stresses. For grade 4B patient who undergo anterior surgery, bony compression was often difficult to remove and always accompanied by adjacent stenosis, simple anterior surgery was difficult to achieve a satisfactory improvement rate. That's why we indicated a patients with 4B would receiver a posterior surgery.

There are also many limiting factors in our research. First, patients with grade 3B and 4B have a small sample size. This will reduce the credibility of our results. Second, this study was conducted at a single medical research center. And a multi-center research is needed, in order to ensure the universality of the classification. Third, Lack of forward-looking research. In order to verify the effect of our grading system on clinical practice, we will continue to track the outpatient, grade them by stenosis and collect them outcomes.

\section{Conclusions}

As suggested by Ganau et al.[34] the diagnosis and treatment of DCM has been evolving over the past 5 decades as a result of collaborations between clinicians and scientists. Spine surgeons are witnessing a fast-paced evolution in basic and clinical research which include advances in imaging and clinical diagnostic tools supporting new surgical techniques, and reparative/regenerative strategies. Our study suggests that a new grading system could improve the interobserver agreement and provide clinicians with a reliable assessment tool to guide clinical treatment for patients with DCM resulting from CCS.

\section{Abbreviations}

CCS: Cervical Canal Stenosis; MRI:Magnetic Resonance Imaging; CT:Computed Tomography; CSF:cerebrospinal fluid; ESSC:effective sagittal spinal canal; ICC:intraclass correlation coefficient; mJOA score:modified Japanese Orthopedic Association Score; DCM:degenerative cervical myelopathy. 


\section{Declarations}

Ethics approval and consent to participate.

This study was approved by medical ethics regulations of the Medical Ethical Committee of Qilu Hospital of Shandong University (Jinan, China), and informed consent was not required.

\section{Consent for publication}

Not Applicable.

\section{Availability of data and material}

The datasets used and/or analyzed of this study are available from authors on reasonable request.

\section{Competing interests}

The authors declare that they have no competing interests

\section{Funding}

The study was supported by Shandong University Qilu Hospital Clinical Practical New Technology Fund (2019-8) , in the role of design of the study, collection, analysis data and writing manuscript.

\section{Author contributions}

Study concept and design: LC, SW, XP, LN

Acquisition of data: SW, JS, JW

Analysis and interpretation of data: SW

Statistical analysis: SW

Drafting of the manuscript: SW, YZ, LC

All authors read and approved the final manuscript

\section{Acknowledgements}

There was no Applicable options

\section{References}

1. Li Z, Xue Y, He D, Tang Y, Ding H, Wang Y, Zong Y, Zhao Y: Extensive laminectomy for multilevel cervical stenosis with ligamentum flavum hypertrophy: more than 10 years follow-up. European spine journal: official publication of the European Spine Society, the European Spinal Deformity Society, and the European Section of the Cervical Spine Research Society 2015, 24(8):1605-1612.

2. LM LT, RK I, AR PMK. W, M K, MG F: Significant Predictors of Outcome Following Surgery for the Treatment of Degenerative Cervical Myelopathy: A Systematic Review of the Literature. Neurosurg Clin North Am. 2018;29(1):115-27.e135. M, M G, JR. 
3. Aebli N, Ruegg TB, Wicki AG, Petrou N, Krebs J. Predicting the risk and severity of acute spinal cord injury after a minor trauma to the cervical spine. The spine journal: official journal of the North American Spine Society. 2013;13(6):597-604.

4. Zhou H, Liu ZJ, Wang SB, Pan SF, Yan M, Zhang FS, Sun Y. Laminoplasty with lateral mass screw fixation for cervical spondylotic myelopathy in patients with athetoid cerebral palsy: A retrospective study. Medicine. 2016;95(39):e5033.

5. Boijsen E. The cervical spinal canal in intraspinal expansive processes. Acta radiologica. 1954;42(2):101-15.

6. Pavlov H, Torg JS, Robie B, Jahre C. Cervical spinal stenosis: determination with vertebral body ratio method. Radiology. 1987;164(3):771-5.

7. Sadler C. Neurapraxia of the cervical spinal cord with transient quadriplegia. The Journal of bone joint surgery American volume. 1987;69(5):794.

8. Fu MC, Webb ML, Buerba RA, Neway WE, Brown JE, Trivedi M, Lischuk AW, Haims AH, Grauer JN. Comparison of agreement of cervical spine degenerative pathology findings in magnetic resonance imaging studies. The spine journal: official journal of the North American Spine Society. 2016;16(1):42-8.

9. Xu BS, Xia Q, Ma XL, Yang Q, Ji N, Shah S, He J, Liu Y. The usefulness of magnetic resonance imaging for sequestered lumbar disc herniation treated with endoscopic surgery. J X-Ray Sci Technol. 2012;20(3):373-81.

10. Modic MT, Weinstein MA, Pavlicek W, Starnes DL, Duchesneau PM, Boumphrey F, Hardy RJ Jr. Nuclear magnetic resonance imaging of the spine. Radiology. 1983;148(3):757-62.

11. Muhle C, Metzner J, Weinert D, Falliner A, Brinkmann G, Mehdorn MH, Heller M, Resnick D. Classification system based on kinematic MR imaging in cervical spondylitic myelopathy. AJNR American journal of neuroradiology. 1998;19(9):1763-71.

12. Janes JG, Garrett KS, McQuerry KJ, Pease AP, Williams NM, Reed SM, MacLeod JN. Comparison of magnetic resonance imaging with standing cervical radiographs for evaluation of vertebral canal stenosis in equine cervical stenotic myelopathy. Equine veterinary journal. 2014;46(6):681-6.

13. Kang Y, Lee JW, Koh YH, Hur S, Kim SJ, Chai JW, Kang HS. New MRI grading system for the cervical canal stenosis. AJR American journal of roentgenology. 2011;197(1):W134-40.

14. Karpova A, Arun R, Davis AM, Kulkarni AV, Mikulis DJ, Sooyong C, Rabin D, Craciunas S, Smith SR, Hansen MA, et al. Reliability of quantitative magnetic resonance imaging methods in the assessment of spinal canal stenosis and cord compression in cervical myelopathy. Spine. 2013;38(3):245-52.

15. Melhem ER. Technical challenges in MR imaging of the cervical spine and cord. Magn Reson Imaging Clin N Am. 2000;8(3):435-52.

16. Yukawa $Y$, Kato F, Yoshihara H, Yanase M, Ito K. MR T2 image classification in cervical compression myelopathy: predictor of surgical outcomes. Spine. 2007;32(15):1675-8. discussion 1679.

17. Park MS, Moon SH, Lee HM, Kim TH, Oh JK, Lee SY, Oh JB, Riew KD. Diagnostic value of oblique magnetic resonance images for evaluating cervical foraminal stenosis. The spine journal: official journal of the North American Spine Society. 2015;15(4):607-11.

18. Bednarik J, Kadanka Z, Dusek L, Kerkovsky M, Vohanka S, Novotny O, Urbanek I, Kratochvilova D. Presymptomatic spondylotic cervical myelopathy: an updated predictive model. European spine journal: official publication of the European Spine Society the European Spinal Deformity Society the European Section of the Cervical Spine Research Society. 2008;17(3):421-31.

19. Bednarik J, Kadanka Z, Dusek L, Novotny O, Surelova D, Urbanek I, Prokes B. Presymptomatic spondylotic cervical cord compression. Spine. 2004;29(20):2260-9.

20. Landis JR, Koch GG. The measurement of observer agreement for categorical data. Biometrics. 1977;33(1):159-74.

Page $11 / 14$ 
21. Gibson JN, Depreitere B, Pflugmacher R, Schnake KJ, Fielding LC, Alamin TF, Goffin J. Decompression and paraspinous tension band: a novel treatment method for patients with lumbar spinal stenosis and degenerative spondylolisthesis. The spine journal: official journal of the North American Spine Society. 2015;15(3 Suppl):23-32.

22. Chang V, Holly LT. Controversies in the management of cervical spondylotic myelopathy. J Neurosurg Sci. 2013;57(3):241-52.

23. Zhang JT, Wang LF, Liu YJ, Cao JM, Li J, Wang S, Shen Y. Relationship between developmental canal stenosis and surgical results of anterior decompression and fusion in patients with cervical spondylotic myelopathy. BMC Musculoskelet Disord. 2015;16:267.

24. Shigematsu H, Ueda Y, Koizumi M, Takeshima T, Tanaka Y, Satoh N, Matsumori H, Oshima T, Matsuyama E, Kugai A, et al. Does developmental canal stenosis influence surgical results of bilateral open-door laminoplasty for cervical spondylotic myelopathy? Journal of neurosurgery Spine. 2008;9(4):358-62.

25. Harrop JS, Naroji S, Maltenfort M, Anderson DG, Albert T, Ratliff JK, Ponnappan RK, Rihn JA, Smith HE, Hilibrand A, et al. Cervical myelopathy: a clinical and radiographic evaluation and correlation to cervical spondylotic myelopathy. Spine. 2010;35(6):620-4.

26. Laurencin CT, Lipson SJ, Senatus P, Botchwey E, Jones TR, Koris M, Hunter J. The stenosis ratio: a new tool for the diagnosis of degenerative spinal stenosis. International journal of surgical investigation. 1999;1(2):127-31.

27. Hammouri QM, Haims AH, Simpson AK, Alqaqa A, Grauer JN. The utility of dynamic flexion-extension radiographs in the initial evaluation of the degenerative lumbar spine. Spine. 2007;32(21):2361-4.

28. Stafira JS, Sonnad JR, Yuh WT, Huard DR, Acker RE, Nguyen DL, Maley JE, Ramji FG, Li WB, Loftus CM. Qualitative assessment of cervical spinal stenosis: observer variability on CT and MR images. AJNR American journal of neuroradiology. 2003;24(4):766-9.

29. Morio Y, Teshima R, Nagashima H, Nawata K, Yamasaki D, Nanjo Y. Correlation between operative outcomes of cervical compression myelopathy and mri of the spinal cord. Spine. 2001;26(11):1238-45.

30. Kovalova I, Kerkovsky M, Kadanka Z, Kadanka Z Jr, Nemec M, Jurova B, Dusek L, Jarkovsky J, Bednarik J. Prevalence and Imaging Characteristics of Nonmyelopathic and Myelopathic Spondylotic Cervical Cord Compression. Spine. 2016;41(24):1908-16.

31. Park HJ, Kim SS, Chung EC, Lee SY, Park NH, Rho MH, Choi SH. Clinical correlation of a new practical MRI method for assessing cervical spinal canal compression. AJR American journal of roentgenology. 2012;199(2):W197-201.

32. Meyer F, Borm W, Thome C. Degenerative cervical spinal stenosis: current strategies in diagnosis and treatment. Deutsches Arzteblatt international. 2008;105(20):366-72.

33. MG SKMG. F: Surgical decision-making in degenerative cervical myelopathy - Anterior versus posterior approach. Journal of clinical neuroscience: official journal of the Neurosurgical Society of Australasia. 2018;58:7-12.

34. LT MG. H, J M, MG F: Future Directions and New Technologies for the Management of Degenerative Cervical Myelopathy. Neurosurg Clin North Am. 2018;29(1):185-93.

\section{Figures}




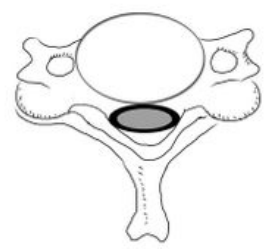

\section{Grade 0}
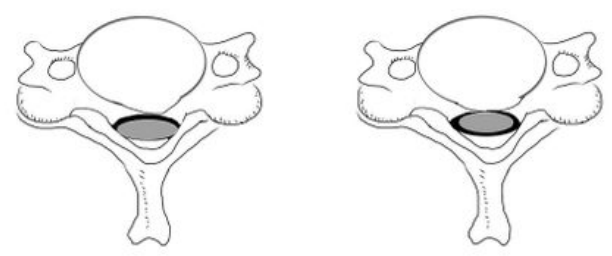

\section{Grade 1}

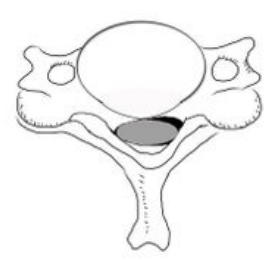

Grade 2
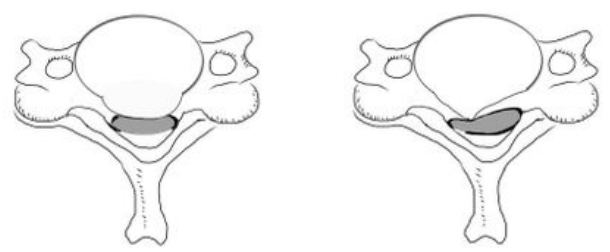

\section{Grade 3A Grade 3B}
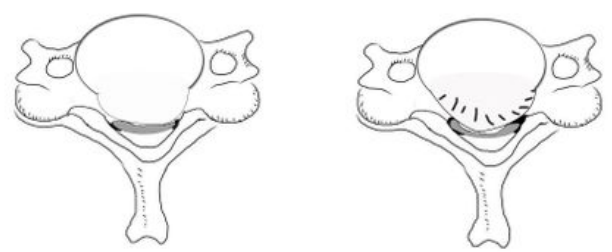

\section{Grade 4A Grade 4B}

\section{Figure 1}

Schematic diagram of grading system for Cervical Canal Stenosis in T2-weighted axial MRI. Grade 0 is normal; Grade 1, mild canal stenosis with obliteration of anterior or posterior of CSF space; Grade 2, moderate canal stenosis with obliteration of both sides of the CSF space but no Significant changes in spinal morphology; Grade 3, severe canal stenosis with spinal cord deformity, grade3A: the degree of cervical spinal cord compression is below $50 \% \bigotimes$ the cervical spinal cord compression ratio is between 0.4-0.2, grade 3B, severe canal stenosis with spinal cord deformity and the angle of the compressive mass less than $90^{\circ}$; grade 4, severe cervical spinal stenosis with cervical spinal cord malformation, cervical spinal cord compression is over $50 \%$ \the cervical spinal cord compression ratio is less than $0.2 \nabla$ grade $4 \mathrm{~A}$, the nature of the herniation is non-bony , grade 4B: the herniation is the ossify mass. 


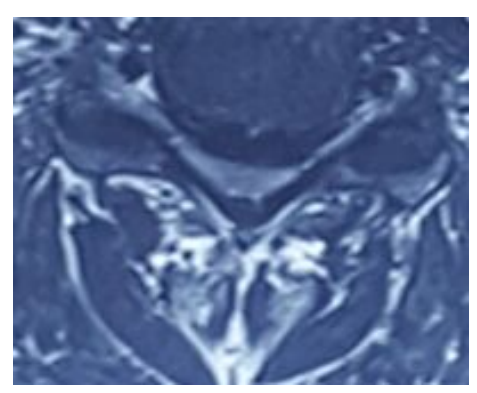

\section{Figure 2}

A patient with serious canal stenosis. Axial T2-weighted MRI shows grade 4A stenosis with a $0.5 / 1.6 \approx 0.3125$ compression ratio at $\mathrm{C} 3 / 4$ level. This patient received a anterior decompression surgery.

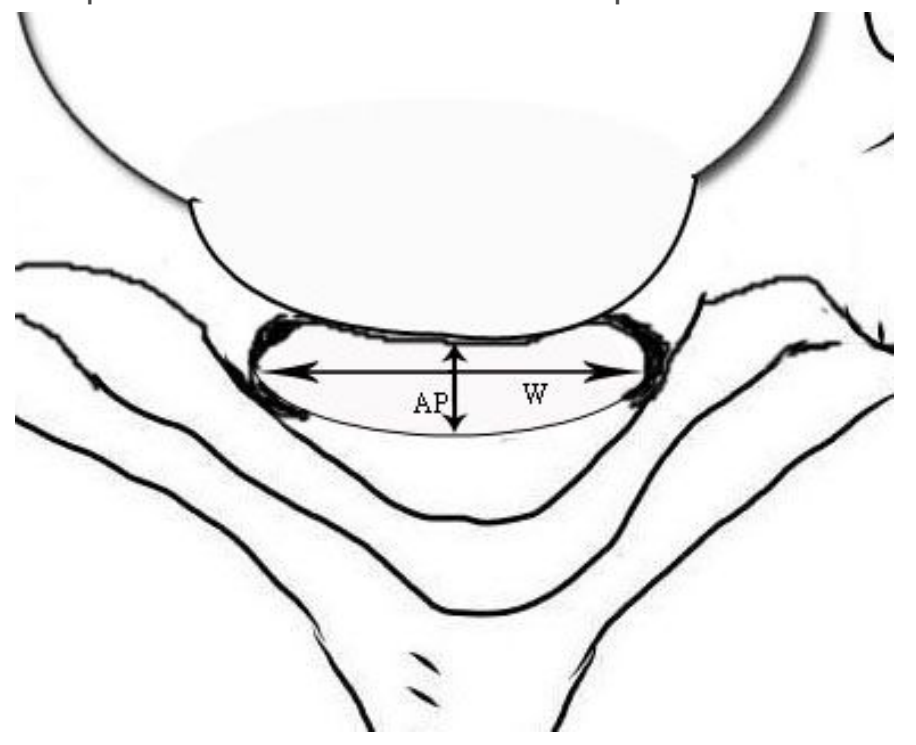

Figure 3

The compression ratio of cervical spinal cord is evaluated by AP/W.AP is the shortest sagittal diameter of cervical spinal cord. And W is the longest transverse diameter of cervical spinal cord. 